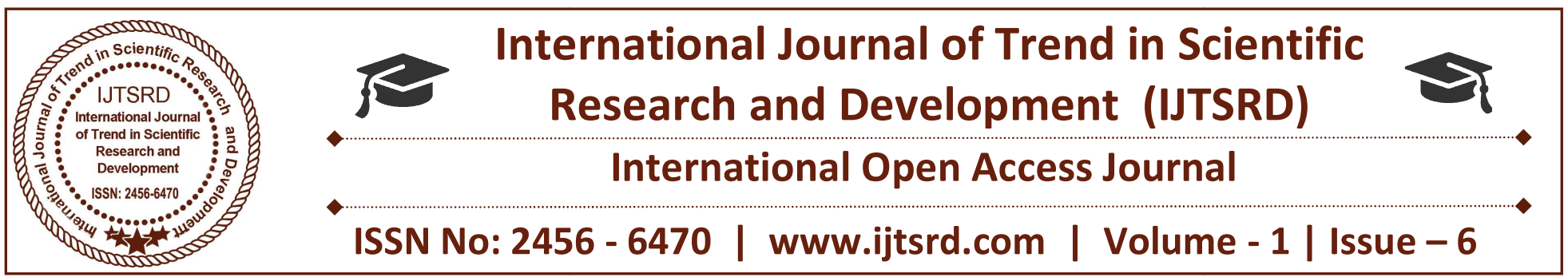

\title{
Dental Anxiety and the Paradox of Gender
}

\author{
Dr. N. Sharon Sucharitha Gold \\ B.D.S., M.A. (Psychology) \\ Salem Mansions, Maruthinagar, Kadapa, A.P., India
}

\section{ABSTRACT}

Objectives: Dental anxiety has been considered as one of the several important obstacles for the patients of dental problems to seek timely treatment from dentists. Applying dental anxiety scales several researchers all over the world have found that the dental anxiety is almost universally more among women compared to men except a few cases. This paper therefore aims to critically reflect upon the dental anxiety research findings, in the light of feminist psychological perspective to comprehend the gender dimension of anxiety phenomenon.

Methods: The paper reviews several research papers published in various journals.

Findings: The findings of the dental anxiety research poses problem to feminists' point of view on gendered anxiety, as generic psychological difference between the genders is not valid. Hence one doubts the reliability of these findings and validity of the dental scales. However, if the association between dental anxiety and gender is genuine it calls for an explanation for this universal phenomenon of gender dental anxiety. If the anxiety is gendered then the question is whether gender is socially constructed or biologically determined?

Keywords: Dental anxiety, Gender, Feminist Psychology, Gender Difference

\section{INTRODUCTION}

Psychologists, sociologists and other social scientists, and medical scientists very often blame the modernity for causing considerable stress on individuals and groups affecting physical health as well as psychological wellbeing. The stress could be due to the nature of occupation, work pressure, studies, travels, demands of family etc. The demand for time to accomplish tasks has been one of the by-products of modern techno socio-economic life. A consequence of the stress is the upsurge of depression, anxiety, worry, fretfulness etc. (Hadika, 2012). These psychological states are studied in great measure by psychologists about their origin, their relations with several other factors. They have been engaged in evaluating and finding ways to overcome these maladies. Anxiety in general as one emotive factor that affects individuals has attracted the special attention of psychologists since the beginning, yet it is immensely relevant for its study for the contemporary society.

Dentists are concerned with dental anxiety for a long time as it not only forms an impediment for providing successful dental care to the patients but also affects the development of the profession. In their efforts to address the issue of dental anxiety they have developed Dental Anxiety Scale to study the prevalence and to measure the anxiety among those who seek dental treatment. These scales are tested for validity under different cultural backgrounds, and now are widely used across the globe. The questions at the moment are not related to the scales but application of these scales to study the dental anxiety and the results obtained through these scales. Though psychologists have differentiated state anxiety from trait anxiety, the psychologically oriented dentists have constructed dental anxiety scale to measure state anxiety with reference to the dental treatment independent of trait anxiety. After several tests of 
reliability and validity in different social, cultural backgrounds these scales are considered valid for measuring the dental anxiety and the results normally correspond with the state anxiety. But when a validation is required the dentists have compared the scores of state-trait anxiety scale and dental anxiety scale. In such situations, the state anxiety scores have corresponded with the dental anxiety scores positively but at times the trait anxiety scores did not match with dental anxiety score which in fact negatively supported the state anxiety. But in a few cases, there is correspondence between dental and trait anxiety scores. Therefore, first, the question of validity still looms large so far as the last one is concerned. Second, the question about women showing greater anxiety than men which appears to be a universal dental anxiety phenomenon shall be addressed. In this regard, dental anxiety also varies according to ethnicity as well as in respect of gender. Another important factor is age wherein the gender deviation occurs as the age increases conversely children do not show much gender difference. Thus, it is clear that culture and age play significant role in dental anxiety, that is, society and its culture influences differently on men and women with reference to anxiety. Given the state of affairs it is necessary to examine these findings in the light of the feminist scholarship that questions gender inequality. The present paper is mainly concerned with the latter issue.

\section{Anxiety}

According to Freud, anxiety is "something felt", an emotional state that include feelings of apprehension, tension, nervousness, and worry accompanied by physiological arousal. It is of three types: neurotic anxiety, moral anxiety, realistic anxiety (Feist and Feist, 2009). Freud also observed that anxiety is positive and also it is adaptive in motivating behaviour that helps individuals cope with threatening situations and it is also negative as if it is intensive and indicative of psychological problem which is found prevalent in most psychiatric disorders. Cattell (1965) emphasizes the importance of distinguishing between anxiety as an emotional state and as a personality trait since individual differences exists with reference to anxiety. Spielberger (1989) has contributed much in distinguishing between state and trait anxiety and has developed the state and trait anxiety inventory. According to him, the state anxiety is defined as an unpleasant emotional arousal in face of threatening demands or dangers. The trait anxiety on the other hand reflects the existence of stable individual differences in the tendency to respond with state anxiety in the anticipation of threatening situations. According to the encyclopaedia of psychology, people with anxiety disorders usually have recurring intrusive thoughts or concerns. They may avoid certain situations out of worry. They may also have physical symptoms such as sweating, trembling, dizziness or a rapid heartbeat etc.

\section{Health and Psychology}

Psychology, in a sense, is a very broad field that relates to every aspect of human life including biology and particularly contributes for the wellbeing of individuals. On the other hand health is a universal concern of individuals and societies; to deal with health and illnesses various systems have been developed and efforts are made to restore normal health. The health systems are complex as they intersect with biology, psychology, culture, religion, social, economic, physical environment and others, and they are developed through historical processes of discoveries, inventions and various types of interventions. The definition of health has changed over time. Prior to $460 \mathrm{BC}$ health was considered a divine gift, but it was Hippocrates who drew attention to the environment, personal hygiene and balanced diet to understand health and illnesses. However, the WHO adopted a definition in 1946 at the International Health Conference at New York and that it became a part of the Preamble of the WHO as "Health is a state of complete physical, mental, and social well-being and not merely the absence of disease or infirmity" (Herrman, Saxena, and Moodie, 2005, XVIII) and it came into force since April 7, 1948. It has not been amended since then.

The above definition has a clear mandate for the psychological well-being of an individual when health is concerned. While treating a patient it is imperative to be concerned with the psychological dimension so that it would be a complete health restoration. Health psychology essentially deals with this aspect contributing to the physical health and illness control. The bio-medical practices and health care institutions, while providing the needed health do engender certain psychological stress on the sick person besides curing illnesses on the psyche of the individual. For example, the revelation of heart ailment and the fatal consequences of it to the patient would create an anxiety and tension in the patient and also in those who are concerned with the health care of that individual. Sometimes even the idea of consulting a 
physician or visiting a hospital itself produces psychological uneasiness. This is true even in case of dental treatment wherein tooth extraction or surgery causes immense pain and anxiety or phobia. Thus, such fears and anxieties are quite wide spread throughout the world. It has also been realized that emotional disorder negatively affects the treatment given by a physician, and therefore, it is imperative that a physician should ensure the emotional order of the patient. The anxiety and discomfort of the patient depends on various factors including those of the physical and social environment. The dentists also could realize further that psychological and behavioural factors are associated with dental anxiety in children and as well as in adults and that these could be measured.

\section{Dental Health and Anxiety}

To speak about dentistry, though unknown to many, the dentistry as a science has its origin around 5000 BC. A Sumerian text describes 'tooth worms' as the cause of dental decay. 'Hesy-Re' an Egyptian scribe belonging to the period $2600 \mathrm{BC}$ is often called the first 'dentist'. Hippocrates and Aristotle write about dentistry including the erupting pattern of the teeth, treatment of decayed teeth, etc. The French surgeon who published 'The Surgeon Dentist, A treatise on teeth (Le Chirugien Dentiste)' Pierre Fauchard $(1723 / 1946)$ is credited as being the father of modern dentistry because his book was the first to describe a comprehensive system for the practice of dentistry including basic oral anatomy and function, operative and restorative techniques and denture construction (Phulari, 2013, p 23).

The role of anticipated dental treatment as a trigger for anxiety is a universal phenomenon. The causes for dental anxiety may be direct or indirect. The direct causes may be due to: 1) Personal experience i.e., a previous painful experience or negative past experience. 2) Feelings of helplessness as people cannot speak or see during the dental treatment. They may feel helpless and out of control which may trigger anxiety. 3) General anxiety/natural anxiety that arise when one encounters a new situation. They may be anxious towards any new experience, so there is apprehension during the first dental visit. The indirect causes are the factors which influence a person's perception or belief that the dental treatment will be painful or uncomfortable. These causes can be another person's bad experience or an advertisement or movie featuring a visit to the dentist as horrible or painful.
Similar experiences in general and non-dental contexts may also produce anxieties when a patient visits a dentist with an acute problem. Dental anxiety may have a significant impact on a person's life. The individuals with dental anxiety are subject to the risk of deterioration of oral health with pain and dysfunctions, due to evasion of dental care.

\section{Prevalence of Dental Anxiety}

The poor social and economic circumstances anywhere in the world affect the dental health like general health as the World Health Organization (WHO) has clearly outlined in The Solid Fact (Wilkinson, and Marmot, 2003). The psychological factors are partly, sometime entirely, related to social factors that affect the health of individuals. Perhaps the earliest study relating to dental anxiety and phobia comes as late as in 1971s from Lautch (1971, p 151158). It is found that the patients with dental phobia have significantly higher anxiety score. Dental trauma is found to be the most important etiological factor in dental phobia. The fear of dentistry was studied using a questionnaire to identify fear stimulus and the associated reactions. The sight of the anaesthetic needle, sound and sensation of the drill are rated to be most fear-eliciting stimuli. Expectations of trauma from dentistry, much previous painful experience of dental treatment and perceived ill treatment by dentists are the major sources of the reported fear reactions. Only in late 1970's the systematic study of dental anxiety has emerged.

It is common that psychological and behavioural factors are associated with dental anxiety in children (Brown, Wright, and McMurray, 1986) and the dental anxiety in children may reflect a more general class of anxiety behaviour rather than fears learned in response to a specific situation. The low dental caries are associated with education and economic status of the parents (Wigen and Wang, 2010). The Guideline on Behavior for the Pediatric Dental Patient points out the cultural factors that affect behaviour in dentistry (Clinical Practice Guidelines, 2015, p 180193). The dental health among Danish youth is found to be related to several factors such as sex; social conditions, dental anxiety, pain tolerance and economic status (Lissaau and Friish-Hasche, 1989). Dental Anxiety among patients seeking care at the university dental hospital in Sri Lanka is found to have association with socio-demographic factors. The variable related to past dental experience has a limited 
influence in explaining dental anxiety (Ekanayake, 2003).

The dental anxiety is considered as a public health problem in Australia (Thompson, Stewart, Carter, and Spencer, 1996). About 40 percent of the Dutch population experiences a considerable degree of dental anxiety about dental treatment and more than half of them can be considered as highly anxious (Stouthard and Hoogstraten, 1990). A study in Peshawar, Pakistan, shows 27 percent of the patients is phobic (Mehboob, Khan and Khan, 2011). But the findings of another study in Karachi, Pakistan, reveal that the dental anxiety is found only among three percent of the patients only (Faisal, Zehra, Hussain, Huzaifa Ali, and Faisal, 2015). However, in Tanzania it is quite contradicting that only 1.2 percent of the sample has shown prevalence of high dental anxiety (Minja, Jovin, and Mandari, 2016). It is reported in high levels among the Trinidadian adults (Naidu and Lalwah, 2010). Several studies in India have revealed dental anxiety among those who visited dental hospitals and clinics (see Acharya, 2008); Appukuttan, Subramanian, Tadepalli, and Damodaran, 2015; Appukuttan, Tadepalli, Cholan, Subramanian, and Vinayagavel, 2013; Bhalla, Bhalla, Singh, and Choudhary, 2013; Bhola and Malhotra, 2014; Ganesh, Goswami and Munshi, 2014; Malvania and Ajithkrishnan, 2011; Mathur, Jain, Vardan, Prabu Duraiswamy, and Kulkarni, 2010; Nair, Shankarapillai, Rai, Ragotham, and Babu, 2010; Nirmala, Quadar, and Dasarraju, 2016; Sharma, Majumder, Rao, Arya, Siwach, and Gulia, 2015; Shavez, Fatima, and Bey, 2015; Suresh, Shitole, Kumar, Parkar, Patil, and Ashwinirani, 2015;), and one study has reported as high as 50.2 percent of the patients (Marya, Grover, Jnaneshwar, Pruthi, and Rustagi, 2012)

\section{Dental Anxiety Scales}

The dental anxiety has been a major inhibiting factor in seeking dentists' timely treatment, delaying dental care, visiting dentists irregularly, evading dental treatment ( Berggren, 1993; Sartory, Heinen, Pundt, and Jöhren, 2007) developing negative attitude towards dentists ( Mathur et al., 2010) etc. It has become an issue of important dental public health concern. It is a complex matter related to psychology, socio-economic factors, and culture of society. Therefore, dealing with dental anxiety has emerged as a new of field of dentistry (Srivastava and Anuradha, 2013). Screening the patients for anxiety (Berggren,
Carlsson, Hakeberg, Hägglin, and Samsonowitz, 2009), predicting anxiety (Agrawal and Das, 2013) and measuring anxiety, employing intervention strategies - videographic intervention (Carpenter, Gatchel, and Hasegawa, 2010), randomization (Armitage and Reidy, 2012), hypnotherapy (Rodolfa, Kraft, and Reilley 2011; Finkelstein, 1991) etc., are the methods adopted to resolve the problem of dental anxiety, if there is any, before the treatment begins.

The dental scales commonly used by dentists are: Corah's Dental Anxiety Scale (CDAS), Modified Dental Anxiety Scale (MDAS), State -Trait Anxiety Scale (STAI), General Geer Fear Scale and Getz Dental Belief Survey, Beck Anxiety Inventory Scale (BSIS), and Visual Analogue Scale (VAS). Among all Corah's dental anxiety scale (Corah, 1969; Corah, Gale, and Lllig, 1978) has been used extensively in epidemiology and clinical research. It is brief and claimed to have good psychometric properties. However, it does not include any reference to local anaesthetic injections, a major focus of anxiety for many. Also, the multiple choice answers for three of the four questions are not clear in the order of severity as the CDAS intends to measure. The answers differ among the questions making them difficult to compare. They include descriptions of psychological reactions and anxiety but at the same confusing to a degree as they are loosely related to components of the experience.

Klienknecht, Klepac, and Alexander, (1973) and Kleinknecht, and Bernstein, (1978) modified the CADS to overcome the above problems. It is known as the Modified Dental Anxiety Scale (MDAS 2012). It is one of the most frequently used instruments to measure the dental fear in international epidemiological studies for over 30 years. This scale used in behavioral research studies which presents good stability, high reliability, acceptable validity in diverse cultures and languages. The MDAS consists of questions each with a five category rating scale ranging from 'not anxious' to 'extremely anxious'. This answering scheme is a simplified rating system in comparison with CDAS with four questions to measure the dental anxiety. The MDAS has an extra item about the respondent's anxiety to a local anaesthetic injection. It is more useful in a clinical setting for screening and diagnosing patients with dental anxiety which was developed from CDAS. It is a brief five item questionnaire, and contains multiple choice questions dealing with subjective reaction about going to the dentist, waiting in the dental clinic 
for treatment, anticipating drilling, scaling and local anesthetic injection. It has been found to be reliable and valid cross culturally and translated in different languages like Spanish, Greek, Chinese, Romanian and Turkish.

Hierarchical Anxiety Questionnaire (HAQ), Multidimensional Mood Questionnaire (MDMQ) etc., are other scales and instruments to measure dental anxiety but these are not as popular as the scales mentioned above.

\section{Dental Anxiety and Gender}

In the light of above discussion first the findings of a study that the author has undertaken is presented here briefly as it gives the required impetus for exploring the intricacies of gender issue in the world wide prevalence of dental anxiety, and the latter discussion would be about examining the issues related to other researchers' findings in different cultural backgrounds. The study was conducted in a small town called Kadapa that has a population 344,078 according to 2011 Census of India, and it has a large rural hinterland. The sex ratio is 984 females which is below normal for a healthy population but it is better than all India sex ratio for the sex ratio in India stands at 940 females for 1000 males according to 2011 census. The percentage of urban population is 34.1percent in the district which speaks of the predominant rural background. The percentage of literacy in Kadapa town is 67.88 percent. The town has several colleges that include engineering, medical, polytechnic, and also a university besides other colleges that provide liberal arts and science education at the level of Bachelor's Degree. There are no industries worth to name that provide large employment. The town has several dental private clinics besides a dental college that cater to the dental health needs of the population in the town and surrounding villages. A sample of 120 dental patients is drawn randomly at different dental clinics in the town, and the data are collected using Kleinknecht and Bernstein's (1978) Modified Dental Anxiety Scale (MDAS). Accordingly ratings of the scale 5-18 and $19+$ scores are considered for the categories of 'no anxiety' and 'anxiety' respectively. It was surprizing that in the total sample of 120 respondents distributed equally by gender, only 15 (25\%) females have shown anxiety. There is not a single case of males showing dental anxiety. Independent-samples ttest result of dental anxiety differences and gender shows significance at the level of $p<.0001$. From this observation the present enquiry into the gender difference in the dental anxiety has begun. Further, the study has shown that anxiety is more prevalent among the illiterate women 10 (18.2 percent) than the literate women 5 (7.7 percent) out of the 60 total women respondents. Independent-samples t-test result of dental anxiety differences and literacy shows significance at the level of $p<.042$. Thus, illiterate women tend to show more anxiety when compared to the literate. The other factors such as rural or urban residence and earlier experience or no experience have not shown any association with anxiety (Gold, 2016).

Women are found to be significantly more anxious than males in the studies carried out in several parts of India such as Gujarat (Malvania and Ajithkrishnan, 2011), in Faridabad (see Marya, et al., 2012), in Thuruvalluvar in Tamilnadu (Ganesh, Goswami and Munshi, 2014), in Chennai (Appukuttan, et al., 2015), in Gurgaon, New Delhi (Sharma et al., 2015), in Aligarh (Shavez, Fatima and Bey, 2015), in Western Maharashtra (Suresh, et al., 2015), in Nellore (Nirmala et al., 2016), in rural Haryana (Bhalla et al., 2013) and so on.

In Brazil also women showed higher rates of dental anxiety (Fuentes, Gorenstein and $\mathrm{Hu}, 2009$ ). The studies in Turkey have revealed the same kind of results where women showed higher rates of anxiety compared to men (Sinan, Özdemir, Öztürk, and Polat, 2002); Eroglu, Ataoglu, and Küçük, 2017). Spain is no way different from USA or Brazil or Turkey (Tarazona, Tarazona-Álvarez, Rojo-Moreno, and Peñarrocha-Diago, 2015). A study in Saudi Arabia has shown similar kind of gender difference where women are with higher dental anxiety (Bahammam, 2016). Dental anxiety is prevalent in Dutch, (14\%), Australia (14.9\%) (Hmud, and Walsh, 2009) and in Netherlands (Stouthard, and Hoogstraten, 1990; Stouthard, Mellenbergh, and Hoogstraten, 2007). Thus, it is evident that women suffer from dental anxiety when compared to men everywhere though the rates of anxiety vary from place to place or country to country.

\section{Dental Anxiety and Age}

After the gender it is the age that is closely associated with dental anxiety. It is interesting to note that in the early stages of human development there is no gender difference but as they grow in age, a change in the 
levels of dental anxiety is seen. Several studies have indicated the vital factor of age regarding dental anxiety (see Alaki, Alotaibi, Almabadi, and Alanquri, 2012; Andreatini, Assun, Jos., Borges de Menezes, Losso, 2013; Assunção, Losso, Andreatini, and de Menezes, 2013; Gao, Hamzah, Yiu, McGrath, and King, 2013; Humphris, Dyer, and Robinson, 2009; Leal, Serra, Queiroz, Araújo, Maia Filho, 2013; Mahiepala, Phan, Kieu, Koppen, Hussain, Huang, 2015; Mohammad, Lalithamma, Varma, Srinivas, Krishnamraju, and Shaik, 2014; Pramila, Murthy, Chandrakala, and Ranganath, 2010; Raja, Malik, Bashir, Attaullah, 2015; McLean et al., 2011; Sadana, Grover, Mehra, Gupta, Kaur, Sadana, 2016; Shafi, Alasmri, Mustafa, AlShahrani, Alasmri, Bijle, 2015; Shim, Kim, Jeon, and An, 2015; Turner, Chambers, and Freeman, 2012). This speaks of an important fact about the role of society in the construction of gender and anxiety being an additive trait of women. Perhaps society expects the masculine characters to be brave, courageous, worry free etc., whereas the opposite characters are considered to be the feminine traits. This leads to the other aspect of society that makes individuals as its members through process of socialization in a specific cultural setting which can be termed as ethnicity.

\section{Dental Anxiety and Ethnicity}

The studies indicate that ethnicity has a strong correlation with the anxiety in the United States (McLean et al., 2011). A study carried out in Tanzania about the dental anxiety among the teachers has shown the prevalence of only 1.2 percent of high dental anxiety, and that sex, age, marital status and perceived oral health status have no significant difference on anxiety except the difference in education of the teachers. But as mentioned earlier 40 percent of the Dutch population experiences dental anxiety and it is considered to be one of the public health problems in Australia. It is prevalent in Norway (see Kvale, Berg, Nilsen, Raadal, Nielsen, Johnsen, and Wormnes, 1997) and Turkey (see Llguy, 2005). However, studies have not been focused so far determining the role of ethnicity or culture on the dental anxiety (Remes, 2016).

\section{Feminism}

In the light of above, it is necessary to examine the issue of dental anxiety at this stage from feminist perspective as the gender difference is conspicuous. It is an empirical reality and demands explanation for such reality of psychological disposition. Anxiety disorders are estimated to be high among women than men in the ratio of $1: 1.7$ in the United States for the rates of lifetime anxiety disorders and it is $1: 1.9$ in 12 months' prevalence. Women showed higher rates of lifetime diagnosis of several anxiety disorders except the social anxiety wherein there is gender difference (Anxiety and Depression Association of American, 2016; McLean, Asnaani, Litz, and Hofmann, 2011, Harvard Health Publications, Harvard medical school. 2008). Therefore, it is needless to emphasize that it shall be the matter of concern for the feminists. Feminism as a social movement and political ideology emerged in Europe in late $19^{\text {th }}$ century and spread to America in $20^{\text {th }}$ century. The belief in feminism holds that men and women are inherently of equal worth. Gender is basically a social construction; anatomical differences of sex of the individuals do not naturally and necessarily lead to certain same characteristics due to same genitals. The gender is an ascription of the society. In several societies men are more privileged than women. The traditional thinking was that man was superior to woman in terms of reason, and masculinity was equated with human rationality of men, and women were marked with sexuality, emotion and their bodies. Women were irrational, weak, vicious and sinful. Feminism is a reaction to this gender bias arguing equality of sexes. In Victorian age literature, women were portrayed as "deviants" or "hysterical", but such depictions no longer found to be valid since 1960 s as the feminist movement began to rise (Woods, n.d.). The feminist theorists question men's appropriation of humanity to themselves and the myth of masculine superiority. In 1800 's the social movement that voiced against gender discrimination and demanded equality of sexes was termed simply as women moment. After 1910 it obtained political identity with an ideology calling for liberation of women.

By the end of World War I feminism became an international movement, between World War I and II. After the World War II women filled the gaps created by the shortage of men in employment; women took up men's work particularly in industries and offices and this proved their capacities equal to those of men. They in a way realized their full potentiality and also secured right to vote in general elections and obtained legal recognition of sexual equality later on. With this the momentum gained and entered into public discourse and academic debates and discussions. However, it emerged in an urban and industrialized environment, having been influenced by socialist 
political ideology. Feminism has passed through at least three waves so far. The first wave that occurred before 1960s has been labelled as 'liberal feminism' that limited to itself mainly lobbying for equal job opportunities for men and woman according to their choices, raising voices against gender discrimination, equal treatment for boys and girls in schools etc. It was basically a movement of the middle class western and white women. The second wave began in the 1960 s and continued into the 1990s, which is more 'radical' than the first. It gained its strength with the rise of New Left movement and joining of marginalized and minority groups. Much of its focus was on equal rights, reproductive rights and social equality. The third wave that began in the middle of 1990s was informed by post-colonial and post-modern thinking. This phase was characterized by redefining feminism in its own terms questioning the universal womanhood, heteronormativity, sexuality, gender etc. It also refused the binaries of us-them, "feminists" and others (Gardiner, 2005). Some are of the view that the fourth wave is emerging with the internalization of gender issues, violence committed against women, and development of electronic media (Rampton, 2015)

\section{Feminist Psychology}

Within the general framework of feminism feminist psychology took its birth that can be traced as far back as 1922. Selvira Draganović (2011) says that Karen Horney may be called as the first feminist psychologist for she wrote that female psychology has been thus far "under the spell" of a male point of view and in fact she coined the term 'feminist psychology.' She was a Neo-Freudian psychologist who wrote several articles about women's experiences (Heffner, 2014). Anna Freud and Margaret Mahler are the other that followed Draganović. However, Naomi Weisstein began the modern course of feminist psychology in around 1968 (Worell, 2000). The feminist psychological scholarship got recognition in 1970s with the development of feminist oriented psychological theories and also practices that encouraged sense of gender equality. However, it is not free from the challenges coming from the mainstream psychology, and thus it itself is a struggle. Clara Thompson, Helene Deutsch, Jean Baker Miller, Phyllis Chesler and Juliet Mitchell are important feminist psychologists. A separate journal has also been started with the title 'Feminism \& Psychology' since 1991 (Macleod. Marecek. and Capdevila, 2014).
The feminist psychologists challenged the androcentric view of psychological knowledge claiming that women were evaluated on male standards and even the subjects were drawn predominantly from males and even the topics covered were male concerns such as aggressiveness, achievement etc. Draganović (2011) states there are eight tenets for feminist psychologists such as inclusiveness, equality, seeking new knowledge, attending the context, acknowledging values, advocating change, attending to process, and expanding psychological practice (Worell and Remer, 2002, p16-17). The feminist psychologists questioned Freud's theories such as "penis envy" and hysteria and termed them as gender biased. According to feminist psychologist the gender stereotypes are constructed without considering experiences of women. Important contributions of feminist psychology have been towards woman's sexuality, violence against women, woman's mental health and wellbeing. Further it has diversified its field towards race, ethnicity, social class, sexual orientation, bisexuality etc. One important contribution of feminist psychologist is the revision of therapeutic practices where women assert gender equality and shed inferiority (Worell, 1980).

A significant theoretical division among the feminist psychologist scholars is with reference to constructivism and essentialism of gender. According to the former, the women are in no way different from men and the differences between them are socially constructed, while the latter consider that women's development is not only different from men but they are also better human beings. An important aspect of scholarship pertains to incorporation of color and diversity of women to move beyond ethnic boundaries and societies. Further, the feminist psychologists have been trying to develop different lines of research and methodologies. Importantly, for feminist clinical psychology it is necessary to call attention on to how the day-to-daylife of women is shaped by gender inequality, and relations of inequality give rise to conflict, frustration, and demoralization (Marecek and Hare-Mustin, 1991). While the main stream of psychology heavily depends on quantitative analysis the feminist psychology calls for the need for qualitative analysis in subjectivist approach with reference to mental disorders (Hornstein, 2013).Some of them have questioned Diagnostic and Statistical Manual of Mental Disorders (DSM) (Hornstein, 2013; Lafrance and McKenzie-Mohr, 2013). Distinct 
feminist therapy has also been suggested (Draganović, 2011). The feminist psychologists developed a new paradigm called intersectionality that takes into other differences also including the gender for the analysis of psychological disorders (Shields, 2008; Davis 2008).

\section{Dental anxiety and State-Trait anxiety}

In the light of above theoretical positions of feminists in general and feminist psychologists in particular, it is imperative to ask whether the gendered dental anxiety is a culturally/socially or psychologically driven phenomenon or it is the interplay of both. The dentists are not concerned with the ontological questions of anxiety except that the dental procedures and treatment trigger anxiety. The dental treatment is a stimulus causing responses from an individual, who is a social being under the influence of the society. The anxiety that develop or emerge as responses of the individual to general class of stimulus within the social and cultural framework of individual's psychological condition or disposition is termed as trait anxiety and the response to a particular stimulus is termed as state anxiety. Interdependency of state and trait anxiety cannot be ruled out. The psychologists have developed scales to measure the state as well as trait anxiety of individuals. The dental anxiety scores are required to correspond with the state anxiety scales.

In this complex psychological process McLean et al., (2011) have doubted applicability of the scales developed in the West in non-Western and nonEuropean contexts. Hence they tried to incorporate non-Western samples for controlling gender and race to standardize the anxiety scales. One way of validation of a dental scale was to examine it by comparing with State-Trait Anxiety Scales and in most of the cases no difference has been noted between dental scale scores and State anxiety scores. But in some cases differences are found and such differences are attributed to ethnic and cultural variations.

Among the American dental patients the state-trait anxiety scores differed with the dental anxiety scores obtained through DAS. While the state anxiety showed higher rates with the dental anxiety, the trait anxiety showed no difference. Weisenberg, Kreindler and Robert (1974) in this regard write,
These correlations would indicate that the DAS is partially measuring the same phenomena as the state anxiety subscale but not of the trait anxiety subscale. These results support the validity of the DAS as a measure of situationally aroused anxiety. (p 946)

Fuentes, Gorenstein and $\mathrm{Hu}$ (2009) make the following observation in their study in Brazil:

"The major finding of this study was a significant association between dental anxiety and trait anxiety. However, an important consideration must be pointed out. Our data indicate that subjects with high dental anxiety tend to present high trait anxiety, yet the opposite is not true, such that high trait anxiety individuals seem not to present a predisposition to dental anxiety." ... "Based on the present data, we strongly believe that subjects with high DAS scores have a high likelihood of also showing high STAI-T scores. This may lead to different planning for this type of patient, for example referral to mental health professionals. A multidisciplinary network of healthcare practitioners would design a more efficacious treatment for the patient."'(p 2)

Yet in another study it is found that in both the scales the women showed higher rates. Further, it has also been found that there is correlation between trait and dental anxiety among the children, adolescents and their parents in Brazil (Andreatini et. al., 2013).

A study in Tukey has shown that though there is no difference in trait anxiety between the genders but the state anxiety is found to be more among women than men. The study was conducted before the patient actually went for surgical treatment at the Oral and Maxillofacial Surgery Department of Cumhuriyet University, Turkey (Sinan, et al., 2002). But in another study it is found that there is strong correlation between the trait scores and the dental anxiety scores. Women have higher rates in both trait as well as dental anxiety scores (Akarslan, Erten. H., Uzun. Işeri, and Topuz, (2010) 2008). Yet another study supports the same view based on the scales of State-Trait Anxiety Inventory (STAI), Dental Anxiety Scale (DAS), and Dental Fear Scale (DFS) where socio-cultural structures have significant role to play in dental anxiety (Eroglu, Ataoglu, Küçük, 2010). In Poland it is found that both State and Trait anxieties are significantly correlated with Corah's Dental Anxiety Scale. Hence the dental anxiety is seen as a 
general anxiety close associated with sociodemographic characters (Olszewska-Czyż, Kantorowicz, and Chomyszyn-Gajewska, 2016).

The scores of the Arabic version of the STAI-Y has been found to be consistent with the MDAS and VAS among the Saudi adult dental patients. The women are found to be more with anxiety levels compared to men and similarly the younger adults show higher anxiety levels than the older patients (Bahammam, 2016). In a Spanish study it is found that patients with higher trait and state anxiety are found with the dental anxiety as well. However, women are found to be with dental anxiety more than men (Tarazona, et al., 2015). The above discussion makes it clear that the State-Trait scales do not necessarily show association with dental anxiety scales in every case. The trait scales do not require measuring the dental anxiety, yet in some case we find correlation between these two. However, what is important is that the state scale is required to correspond with the dental anxiety and in most of the cases they do not correspond completely but partially. Thus, the dental anxiety scales can measure the psychometric anxieties generated by dental procedures to some extent, but there are gaps to be filled.

\section{Discussion and the paradoxes}

If the dental anxiety measurements are to be accepted and women show higher rates of anxiety, do we have to accept the fact that dental anxiety behavior is inherently sex related phenomenon? Then, how does a feminist and a feminist psychologist scholarship that asserts gender equality explains this? Is not dental anxiety related to social construction of gender? Do we construe that women respond differently from men so far as dental anxiety is concerned? One answer could be the dental anxiety levels are required to be examined from the perspective of feminist psychology to rule out that the scales are constructed keeping male standards. Further, the state-trait anxiety scales are to be subjected to the same consideration. Another partial answer for these questions is from the cultural and ethnic difference. As mentioned above, the levels of anxiety are different in different cultures. However, this observation requires support from detailed crosscultural studies. The establishment of cultural variation can only support feminists' assertion of gender equality. Further, the dental anxiety that does not differentiate sex of the child speaks about the influence of culture as the child grows into an adult. As the child grows the girl child continues to hold more anxiety while the male child is able to control the anxiety. According to Anxiety and Depression Association of America specific phobia develops among women twice as likely as it is with men, and it sets in children at a median age of 7 (ADAA 2016) and cross-culturally it is 8.7 (McLean et al., 2011). But in fact the hormonal changes that occur rapidly after this age, influence the sexuality of the child. Therefore, there is a need to understand the correspondence between the growth of the individual and the changes that occur in anxiety level for establishing the age association with anxiety besides the influence of society on the individuals.

However, there is another challenge coming from the biological basis of gendered anxiety. Based on the studies of Corticotropin-Releasing Factor (CRF), a hormone that organizes stress responses in mammals, it is hypothesized that women are more sensitive to low levels of CRF and as such they are less able to adapt to high levels of stress than men. One reason for the differential anxiety seems to lie with the biology of woman, i.e., brain's chemistry of woman that responses to stress differently from that of man (Bangasser, Curtis, Reyes, Bethea, Parastatidis, Ischiropoulos, Van Bockstaele, and Valentino, 2010; Brizendine, 2006; CHOP News, 2010; Remes, 2016; Valentino, and Debra Bangasser, 2016). This is the point that requires serious attention of the feminists as well as feminist psychologists. This can perhaps be addressed from the latter as woman's development which is different from men and it does not make them in anyway inferior to men.

Another explanation for different anxieties expressed is that while woman internalizes emotions man externalizes emotions (Hogan, 2016). Some other argue it isn't that biology of gender is different rather the nature of woman and woman and their responses to stress are different, but that does not make woman inferior to man (Greenberg, 2012).

\section{CONCLUSION}

The dental treatment procedures necessarily induce stress on the patients, and it is universally acknowledged that even the visiting the dentist causes anxiety regardless of age and sex. Since the health restoration practices are required to minimize such effects on the patients, the dentists are concerned about reducing such anxieties. Therefore, they have developed dental anxiety scales analogous to statetrait anxiety scales in general psychology for 
measuring the dental anxieties. The findings of dental anxiety across the world shows prevalence of universally higher rates of anxiety among women compared to men. This finding raises questions on the assertions of feminists and feminist psychologists about the gender equality with reference to psychological behavior. Since the dental scales have been able to obtain validation under different cultural backgrounds, in relation with general state-trait anxiety scales, the association of gender with dental anxiety cannot be denied. However, this finding has bearing on the idea of social construction of gender which is strongly espoused by the feminists in general and feminist psychologists in particular. The implication is that all these scales must be proved that they have been constructed in gender neutrality frame and not constructed on male standards. Though some studies have indicated association of dental anxiety levels with cultural background extensive studies are required to be undertaken in order to support or dispute the association of gender and anxiety which will also bring clarity on the social construction of gender instead of biological determination of gender.

\section{ACKNOWLEDGEMENTS}

The author is greatly indebted to Prof. N. Sudhakar Rao, Department of Anthropology, University of Hyderabad, Hyderabad, for his invaluable suggestions and ideas to develop this paper.

\section{REFERENCES}

1) Acharya, S. (2008). Factors affecting dental anxiety and beliefs in an Indian population. Journal of Oral Rehabilitation 35(4), 259-67. Retried abstract from http://onlinelibrary.wiley.com/doi/10.1111/j.13652842.2007.01777.x/abstract.

2) Agarwal, M., and Das, U.M. (2013). Dental anxiety prediction using Venham Picture test: A preliminary cross-sectional study. Journal of Indian Society of Pedodontics and Preventive Dentistry, 31(1), 22-24.

8) Akarslan, Z. Z., Erten. H., Uzun. O., Işeri. E., and Topuz, O. (2010). Relationship between trait anxiety, dental anxiety and DMFT indexes of Turkish patients attending a dental school clinic. East Mediterr Health Journal, 16(5), 558-62. http://apps.who.int/iris/bitstream/10665/ 117916/1/16_5_2010_0558_0562.pdf?ua=1.

9) Andreatini, R, Assun,C.M., Jos., Borges de Menezes, V.N., Losso.E.M. (2013).The relationship between dental anxiety in children, adolescents and their parents at dental environment. Journal of Indian Society of Pedodontics and Preventive Dentistry, 31 (3), 175-179. doi: 10.4103/0970-4388.117977.

10) Anxiety and Depression Association of American (ADAA) (Updated August 2016) Facts \& Statistics. Retried from https://www.adaa.org/about-adaa/pressroom/facts-statistics.

11) Alaki, S., Alotaibi, A., Almabadi, E., and Alanquri, E. (2012) Dental anxiety in middle school children and their caregivers: Prevalence and severity. Journal of Dentistry and Oral Hygiene, 4(1), 6-11. doi: 10.5897/jdoh11.019 issn 2141-2472.

12) Appukuttan, D., Subramanian, S., Tadepalli, A., and Damodaran, L.K. (2015). Dental anxiety among adults: An epidemiological study in South India. North American Journal of Medical Sciences, 7(1), 13-18.

13) Appukuttan, D.P., Tadepalli, A., Cholan, P.K., Subramanian, S., and Vinayagavel, M. (2013). Prevalence of dental anxiety among patients attending a dental educational institution in Chennai, India - A questionnaire based study. Oral Health Dent Manag, 12(4), 289-94.

14) Armitage, C.J., and Reidy, J.G (2012). Evidence that process simulations reduce anxiety in patients receiving dental treatment: randomized exploratory trial. Anxiety, Stress \& Coping, 25 (2), 155-165.

15) Assunção, C.M., Losso, E.M., Andreatini, R., and de Menezes, J.N. (2013). The relationship between dental anxiety in children, adolescents and their parents at dental environment, Journal of Indian Society of Pedodontics and Preventive Dentistry,31(3), 175-179.

16) Bahammam, M.A. (2016). Validity and reliability of an Arabic version of the state-trait anxiety inventory in a Saudi dental setting. Saudi Med J., 37(6), 668-674. doi:10.15537/smj.2016.6.13935.

17) Bangasser, D.A., Curtis, A., Reyes, B.A.S., Bethea,T.T., Parastatidis, I., Ischiropoulos, H., Van Bockstaele, E. J., and Valentino, R. J. (2010). Sex differences in corticotropin-releasing factor receptor signaling and trafficking: Potential role in female vulnerability to stress-related psychopathology. Mol Psychiatry, 15(9), 877904. doi: 10.1038/mp.2010.66.

18) Berggren, U. (1993). Psychosocial effects associated with dental fear in adult dental patients 
with avoidance behaviours. Psychology \& Health, 8 (2-3), 185-196.

19) Berggren, U., Carlsson, S.G., Hakeberg, M., Hägglin, C., and Samsonowitz, V. (2009). Assessment of patients with phobic dental anxiety. Acta Odontologica Scandinavica, 55(4), 217-222.

20) Bhalla, A., Bhalla, S. S., Singh. A and Choudhary, A. (2013). Self-assessment of dental anxiety in patients visiting comprehensive rural health service project. Journal of Depression and Anxiety, 2,137.

21) Bhola, R., and Malhotra, R. (2014). Dental procedures, oral practices, and associated anxiety: A study on late-teenagers. Osong Public Health and Research Perspectives, 5 (4), 219-232.

22) Brizendine, L. (2006). The female brain. New York: Morgan Road Books.

23) Brown, D. F., Wright, F, A., and McMurray, N. E. (1986). Psychological and behavioral factors associated with dental anxiety in children. Journal of Behavioral Medicine, 9(2), 213-218.

24) Carpenter, D. J., Gatchel, R.J., and Hasegawa,T. (2010). Effectiveness of a videotaped behavioral intervention for dental anxiety: The role of gender and the need for information. Behavioral Medicine, 20 (3), 123-132.

25) Cattell, R.B. (1965). The scientific analysis of personality. Baltimore: Penguin Books.

26) CHOP News (2010). Researchers find gender differences in stress response. Published on Jun 15, 2010. Retrieved from http://www.chop.edu/news/researchers-findgender-differences-stress-response\#.VxZvPjZ1lnZ.

27) Clinical Practice Guidelines (2015). Guideline on behavior for the pediatric dental patient 2015 Reference Manual, 37 (6), 15/16, 180-193.

28) Corah, N.L. (1969) Development of a dental anxiety scale. J. Dent Res, 48(4):596.

a. doi: $10.1177 / 00220345690480041801$.

29) Corah, N.L., Gale, E.N., and Lllig, S.J. (1978). Assessment of a dental anxiety scale. The Journal of the American Dental Association, 97(5), 816-819.

30) Davis, K. (2008). Intersectionality as buzzword: A sociology of science perspective on what makes a feminist theory successful. Feminist Theory, 9(1), 67-85. doi: 10.1177/1464700108086364.

31) Draganović, S. (2011). Approaches to feminist therapy: A case study illustration. Epiphany, 4(1), 110-127.

32) Eagly, A.H., Eaton, A., Rose, S.M., Riger, S., and McHugh, M.C. (2012). Analysis of a half-century of research on women and gender. American Psychology, 67(3), 211-30. doi: 10.1037/a0027260.Epub 2012 Feb 27.

33) Ekanayake, L. and Dharmawardena, D. (2003). Dental anxiety in patients seeking care at the university dental hospital in Srilanka. Community Dental Health, 20(2), 112-116.

34) Eroglu, C.N., Ataoglu, H., and Küçük, K. (2017). Factors affecting anxiety-fear of surgical procedures in dentistry. Nigerian Journal of Clinical Practice 2/14/2017. Retried from http://www.njcponline.com/preprintarticle.asp?id= 181371 ; type $=0$.

35) Fauchard, Pierre. (1723/1946). The surgeon dentist: Or, treatise on the teeth. London: Butterworth Publisher.

36) Feist and Feist, G.J. (2009). Freud: Psychoanalysis. In Ryan, M. (Ed.), Theories of Personality. (7th ed.,) (pp 16-63). New York, NY: McGraw-Hill.

37) Finkelstein, S. (1991). Hypnotically assisted preparation of the anxious patient for medical and dental treatment. American Journal of Clinical Hypnosis, 33 (3), 187-191.

38) Fuentes, D., C. Gorenstein, C., and Hu, L.W (2009). Dental anxiety and trait anxiety: An investigation of their relationship. British Dental Journal, E17. 206. doi: 10.1038/sj.bdj.2009.253.

39) Ganesh, R., Goswami, C., and Munshi, R. (2014). Comparison of dental anxiety among patients visiting a dental college and private dental clinics in Thiruvallur district, India. SRM Journal of Research in Dental Sciences, 5 (1), 4-20.

40) Gao, X., Hamzah, S.H., Yiu, C.K.Y., McGrath, C., and King, N.M. (2013). Dental fear and anxiety in children and adolescents: Qualitative study using youtube. $J$ Med Internet Res, 15(2):e29. doi: 10.2196/jmir.2290.

41) Gardiner, J.K. (2005). Men, masculinities, and feminist theory. In Michael S. Kimmel, Jeff Hearn, and R.W.Connel (Eds.) Handbook of Studies on Men \& Masculinities. (Chapter 3, 3550). London: Sage Publications Inc.

42) Gold, N.S.S. (2016). A study on the prevalence of dental anxiety in relation to gender, literacy, residence and previous surgical experience among people of Kadapa (Master's Thesis). Indira Gandhi National Open University. New Delhi.

43) Greenberg, T. M. (2012) Differences between men and women. Retried from https://www.psychologytoday.com/blog/21st- 
century-aging/201209/differences-between-menand-women.

44) Hadika, B (2012). Depression as a disease of modernity: explanations for increasing prevalence. J. Affect Disorder, 140 (3), 205-214.

45) Harvard Health Publications, Harvard medical school. (2008). Harvard woman's health watch. Anxiety and physical illness. http://www.health.harvard.edu/stayinghealthy/anxiety_and_physical_illness.

46) Heffner, C.L (2014) Karen Horney's Feminine Psychology Chapter 5: Section 5: Psych Central's Virtual Psychology Classroom. Retried from https://allpsych.com/personalitysynopsis/horney/

47) Herrman, H., Saxena, S., and Moodie, R. (Eds.) (2005). Promoting mental health: Concepts, emerging evidence, practice. Geneva: WHO Press.

48) Hmud, R., and Walsh,L. J. (2009). Dental anxiety: causes, complications and management approaches. Journal of Minimum Intervention in Dentistry, 2, 67-78.

49) Hogan, J. (2016). Why we need to start taking women's anxiety seriously. Retried from http://verilymag.com/2016/04/men-womenanxiety-meds-prescriptions-sex-differencesmental-health.

50) Hornstein, G. A, (2013). Whose account matters? A challenge to feminist Psychologists. Feminism \& Psychology, 23(1), 29-40.

51) Humphris, G.M., Dyer, T.A., and Robinson, P. G. (2009). The modified dental anxiety scale: UK general public population norms in 2008 with further psychometrics and effects of age. $B M C$ Oral Health, 9, 1-8. doi: 10.1186/1472-6831-9-20.

52) Humphris, G.M., Morrison, T., and Lindsay, S.J. (1995). The modified dental anxiety scale: validation and United Kingdom norms. Community dental health. 12(3), 143-150.

53) Hogan, J. L.P.C, Why We Need to Start Taking Women's Anxiety Seriously. Retried from http://verilymag.com/2016/04/men-womenanxiety-meds-prescriptions-sex-differencesmental-health.

54) Kleinknecht, R.A., and Bernstein, D.A. (1978). The assessment of dental fear. Behaviour therapy, 9(4), 626-634. Retried from http://dx.doi.org/10.1016/S0005-7894(78)801385.

55) Klienknecht, R.A., Klepac, R.K., and Alexander, LD. (1973). Origins and characteristics of Fear of Dentistry. Journal of the American Dental Association, $\quad 86(4), \quad 842-848$. doi: http://dx.doi.org/10.14219/jada.archive.1973. 0165.

56) Kvale, G., Berg, E., Nilsen, C.M., Raadal, M., Nielsen, G.H., Johnsen, T.B., and Wormnes, B. (1997) Validation of the dental fear scale and the dental belief survey in a Norwegian sample. Community dentistry and Oral Epidemiology. 25(2), 160-164.

57) Lafrance, M.N., and McKenzie-Mohr,S. (2013). The DSM and its lure of Legitimacy. Feminism \& Psychology, 23(1), 119-140.

58) Lautch, H. (1971). Dental Phobia. The British Journal of Psychiatry, 119 (549) 151158; doi: 10.1192/bjp.119.549.151.

59) Leal, A.M.A., Serra, K.G., Queiroz, R.C.S., Araújo, M.A.R., Maia Filho, E.M. (2013). Fear and/or anxiety of children and parents associated with the dental environment European. Journal of Paediatric Dentistry, 14(4), 269-271. Retried from http://admin.ejpd.eu/download/EJPD_2013_04_03 .pdf.

60) Lissaau, I., Holst, D. and Friish-Hasche, E. (1989). Use of dental services among Danish youths: Role of the social environment, the individual, and the delivery system. Community Dental Oral Epidemiology, 17(3), 109-116. doi: 10.1111/j.1600-0528.1989.tb00001.x

61) Llguy, D. (2005). Reliability and validity of the modified dental anxiety scale in Turkish patients. Journal of International medical Research, 33(2), 252-259. Retried from http://journals.sagepub.com/doi/abs/10.1177/1473 23000503300214.

62) Macleod.C, Marecek. J and Capdevila. R. (2014). Feminism \& Psychology going forward. Feminism \& Psychology, 24(1) 3-17.

63) Mahiepala, N. A., Phan, V.N., Kieu, K.D., Koppen, J.P.L., Hussain, B.H., Huang, B. (2015). Influencing factors of paediatric dental anxiety levels in an undergraduate dental clinic. European Journal of Paediatric Dentistry,16 (2),159-62. pmid: 26147825.

64) Malvania, E.A., and Ajithkrishnan, C.G. (2011). Prevalence and socio-demographic correlates of dental anxiety among a group of adult patients attending a dental institution in Vadodara city, Gujarat, India. Indian Journal of Dental Research - Web Journal, 22 (1), 179-180. Retried from http://www.ijdr.in/text.asp?2011/22/1/179/79989.

65) Marecek, J., and Hare-Mustin, R.T. (1991). A short History of the future Feminism and Clinical 
Psychology. Psychology of Women Quarterly, 15, 521-536.

66) Marya, C.M., Grover, S., Jnaneshwar, A., Pruthi, N., and Rustagi, S. (2012). Dental anxiety among patients visiting a dental institute in Faridabad, India, West Indian Medical Journal, 61(2).

67) Mathur, A., Jain. M., Vardan, Prabu Duraiswamy, and Kulkarni, S. (2010). Negative dentist behaviour among patient's attending dental clinics of Udaipur city, India - a cross sectional study. Journal of Oral Health Research, 1 (1), 40-44.

68) McLean, C. P., Asnaani, A., Litz, B. T., and Hofmann, S.G. (2011). Gender differences in anxiety disorders: Prevalence, course of illness, comorbidity and burden of illness. J. Psychiatric Research, 45(8), 1027-1035.

69) Mehboob, B., Khan, E., and Khan, M. (2011). Dental anxiety scale in exodontia patients. Journal of Khyber College of Dentistry, 1(2), 66-70. Retried from http://www.jkcd.org.pk/Issues/2011/ June/JKCD-3.pdf.

70) Minja, I, K., Jovin, A.C., and Mandari, G.J. (2016). Prevalence and factors associated with dental anxiety among primary school teachers in Ngara District, Tanzania. Tanzania Journal of Health Research, 18 (1). doi: http://dx.doi.org/10.4314/thrb.v18i1.6.

71) Mohammad, R.B., Lalithamma, T., Varma, D.M., Srinivas, B., Krishnamraju, P.V., and Shaik, A.B. (2014). Prevalence of dental anxiety and its relation to age and gender in costal Andhra (Visakhapatnam) population, India. Journal of Natural Science, Biology and Medicine. 5(2), 409-414. doi: 10.4103/0976-9668.136210

72) Naidu, R.S., and Lalwah, S. (2010). Dental anxiety in a sample of West Indian adults. West Indian Medical Journal. 59(5), 567-572. Retried abstract from http://caribbean.scielo.org/scielo.php? script $=$ sci
a. abstract
\&pid $=\mathrm{S} 0043-$
31442010000500021\&lng=pt\&nrm=.pf

73) Nair, M.N.K., Shankarapillai, R., Rai, N., Ragotham, K., and Babu, C.H.S. (2010). Dental anxiety and oral hygiene in Udaipur rural womenA cross sectional study. International Journal of Dental Clinics, 2 (4), 33-35.

74) Nirmala, S.V.S.G,, Akhil Quadar, Md., and Dasarraju, R.K. (2016). Dental anxiety of outpatients in an institutional based dental hospital: A cross sectional study. Journal of Dental Health, Oral Disorders \& Therapy, 4 (1). Retrieved
http://medcraveonline.com/JDHODT/JDHODT04-00099.pdf.

75) Olszewska-Czyż, I., Kantorowicz, M., and Chomyszyn-Gajewska, M. (2016) Investigation of trait anxiety as a predictor of dental anxiety. $J$ Stoma, 69 (4). doi: 10.5604/00114553.1225378.

77) Phulari, B.S., (2013). History of Orthodontics. New Delhi: Jaypee Brothers Medical Publishers (Pvt.) Ltd.

78) Pramila, M., Murthy, A.K, Chandrakala, B., and Ranganath, S. (2010). Dental fear in children and its relation to dental caries and gingival condition - a cross sectional study in Bangalore city, India. Int. Journal of Clinical Dental Science, 1(1). Retried from http://edentj.com/index.php/ijcds/article/viewFile/ 23/22.

79) Raja, G.H., Malik, F.S., Bashir, U., and Attaullah. (2015). Dental anxiety among children of age between 5 to 10 years visiting a teaching dental hospital in Islamabad, Pakistan. J Ayub Med Coll Abbottabad. 27(3):587-90. PMID: 26721014.

80) Rampton, M (2015). Four waves of feminism sunday. Pacific University Center for Gender Equity, Gender and Sexuality Studies Minor. Retried from

a. https://www.pacificu.edu/about-us/newsevents/four-waves-feminism.

81) Remes, O. (2016). Women are far more anxious than men - here's the science. AEST. Retried from http://theconversation.com/women-are-farmore-anxious-than-men-heres-the-science-60458.

82) Rodolfa, E.R., Kraft, W., and Reilley, R.R. (2011). Etiology and treatment of dental anxiety and phobia. American Journal of Clinical Hypnosis, 33 (1), 22-28.

83) Sartory, G., Heinen, R., Pundt, I., and Jöhren, P (2007). Predictors of behavioral avoidance in dental phobia: The role of gender, dysfunctional cognitions and the need for control. Anxiety, Stress \& Coping, 19 (3), 279-291.

84) Sadana G, Grover R, Mehra M, Gupta S, Kaur J, Sadana S. (2016). A novel Chotta Bheem-Chutki scale for dental anxiety determination in children. J Int Soc Prevent Communit Dent. 6 (3), 200-205. doi: 10.4103/2231-0762.183108.

85) Shafi, S., Alasmri, A., Mustafa, A., AlShahrani, A.S.S., Alasmri, H., Bijle, M. N. A. (2015). An assessment of dental anxiety in nonclinical setting among Saudi Arabian children using Abeer Children Dental Anxiety Scale. Journal of Dental Research and Review. 2 (4), 172-174. 
86) Faisal, S., Zehra, N., Hussain, M., Huzaifa Ali, H. J., and Faisal, A. (2015). Dental anxiety among patients attending public and private dental hospitals of Karachi. Journal of the Pakistan Dental Association, 24 (1), 46 - 51.

87) Sharma, S., Majumder, K., Rao, J.K.D., Arya, V., Siwach, V., and Gulia, S. (2015). Assessment of relationship between pain and anxiety following dental extraction - A prospective study. pain studies and treatment, 3, 23-30 Published Online July 2015 in SciRes. Retried from http://www.scirp.org/journal/pstttp://dx.doi.org/10 $.4236 /$ pst.2015.33003.

88) Shavez, Z., Fatima, Z., and Bey, A. (2015). Evaluation of anxiety associated with dental visit and treatment experience: A short study. Dental, Oral and Craniofacial Research, 1(3), 75-76.

89) Shields, S.A. (2008). Gender: An intersectionality perspective. Sex Roles. 59, 301-311. doi 10.1007/s11199-008-9501-8.

90) Shim,Y., Kim,A., Jeon, E., and An, S. (2015). Dental fear \& anxiety and dental pain in children and adolescents; a systemic review. J Dent Anesth Pain Med, 15(2), 53-61. Retried from http://dx.doi.org/10.17245/jdapm.2015.15.2.53.

91) Sinan, A.Y., Özdemir, D., Öztürk, M., and Polat, S. (2002). An assessment of dental anxiety in oral surgery patients. Gulhane Med J, 44(4), 395-398. Retried abstract from http://www.scopemed.org/?mno=5005.

92) Spielberger, C.D. (1989). State-Trait Anxiety Inventory: Bibliography (2nd ed.). Palo Alto, CA: Consulting Psychologists Press.

93) Srivastava, A., and Anuradha, P. (2013). Psychology in dentistry - "An emerging field of dentistry in India". Global Journal of Medicine and Public Health, 2 (5). Retried from www.gjmedph.org Vol. 2, No. 52013.

94) Stouthard, M.E.A, and Hoogstraten, J. (1990). Prevalence of dental anxiety in the Netherlands. Community Dent Oral Epidemiol, 18(3), 139-42.

95) Stouthard, M.E.A., Mellenbergh, G.J., and Hoogstraten, J. (2007). Assessment of dental anxiety: A facet approach. Anxiety, Stress \& Coping, 6 (2), 89-105. Retrieved abstract from http://www.tandfonline.com/doi/abs/10.1080/1061 5809308248372.

96) Suresh, K. V, Shitole, S., Kumar, C. D. M., Parkar, M.I., Patil, P.K., and Ashwinirani, S.R. (2015). Assessment of dental anxiety in patients undergoing surgical extraction of teeth: study from western Maharashtra. British Biomedical Bulletin, 3 (2), 232-238.

97) Tarazona, B., Tarazona-Álvarez, P., RojoMoreno, J. D., and Peñarrocha-Diago, M.A. (2015). Anxiety before extraction of impacted lower third molars. Med Oral Patol Oral Cir Bucal, 20(2), e246-e250. http://dialnet.unirioja.es/servlet/citart?info=link\&c odigo $=5081412$ \&orden $=0$.

98) Thompson, W.M., Stewart, J.F., Carter, K.D., and Spencer, AJ. (1996). Dental anxiety among Australians. International dental Journal, 46(4), 320-324. Retried from https:/www.ncbi.nlm.nih.gov/pubmed/9147119.

99) Turner, S., Chambers, S.A., and Freeman, R. (2012). Measuring dental anxiety in children with complex and additional support needs using the Modified Child Dental Anxiety Scale (faces) (MCDASf). Journal of Disability and Oral Health. 13(1), 3-10

100) Valentino, R.J., and Debra Bangasser. (2016). Sex-biased cellular signaling: molecular basis for sex differences in neuropsychiatric diseases. Dialogues in clinical neuroscience. 18(4), 385393.

101) Weisenberg, M., Kreindler, M. L., and Schachat, R. (1974). Relationship of the dental anxiety scale to the state-trait anxiety inventory. $J$ Dent Res, 53(4), 946.

102) Wigan, T.I., and Wang, N.J. (2010). Caries and back ground factors in Norwegian and immigrant 5-year-old children. Community dental Oral Epidemiology. 38(1), 19-28.

103) Wilkinson, R and Marmot, M. (Eds.) (2003). Social Determinants of Health: The Solid Facts. Copenhagen: International Centre for Health and Society.

104) Woods, T. (n.d) From female sexuality and hysteria to feminine psychology: The gender of insanity in literature. Retrieved from http://www.nyu.edu/classes/keefer/EvergreenEner gy/woodst.pdf.

105) Worell, J. (2000). Feminism in psychology: Revolution or evolution? ANNALS, AAPSS, 571. 